\title{
Expanding Opportunities: Assessing and Addressing Geographic Diversity at the SIGCSE Technical Symposium
}

\author{
Brett A. Becker \\ University College Dublin \\ Dublin, Ireland \\ brett.becker@ucd.ie
}

\author{
Amber Settle \\ DePaul University \\ Chicago, IL, USA \\ asettle@cdm.depaul.edu
}

\author{
Andrew Luxton-Reilly \\ University of Auckland \\ Auckland, New Zealand \\ a.luxton-reilly@auckland.ac.nz
}

\author{
Briana B. Morrison \\ University of Nebraska Omaha \\ Omaha, NE, USA \\ bbmorrison@unomaha.edu
}

\author{
Cary Laxer \\ Rose-Hulman Institute of Technology \\ Terre Haute, IN, USA \\ laxer@rose-hulman.edu
}

\begin{abstract}
The ACM Special Interest Group on Computer Science Education (SIGCSE) is one of the oldest and largest SIGs, and the SIGCSE Technical Symposium is the oldest and largest of the four SIGCSE conferences. However, the vast majority of Symposium attendees and contributors are from the United States. Because SIGCSE is an international organization, this lack of geographic diversity and representation is troubling because it may stifle collaboration, membership, professional development, and dissemination of research, and have many other adverse effects.

In this paper we substantiate the position that there are many reasons to be concerned about poor geographic representation, supported with facts demonstrating that both attendance and authorship at the Symposium are not geographically diverse, particularly for a global organization. We provide evidence that the geographic diversity of SIGCSE membership is substantially more limited than ACM membership, demonstrating that the field of Computing Education is not as diverse as it should be given that the topic is of global interest and importance. We conclude by offering some suggestions that may improve inclusivity and participation in SIGCSE's flagship conference, as well as the Computing Education community in general.
\end{abstract}

\section{CCS CONCEPTS}

- Social and professional topics $\rightarrow$ Computer science education; Computing education; Computing organizations; Geographic characteristics; Race and ethnicity; Cultural characteristics; Professional topics; • General and reference $\rightarrow$ General conference proceedings.

\section{KEYWORDS}

Authorship; Conferences; Conference Attendance; Diversity; Global; Inclusiveness; International; Membership; Participation; SIGCSE; Special Interest Group; Symposium; Technical Symposium

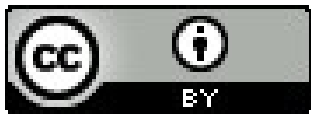

This work is licensed under a Creative Commons Attribution International 4.0 License. SIGCSE '21, March 13-20, 2021, Virtual Event, USA

(C) 2021 Copyright held by the owner/author(s).

ACM ISBN 978-1-4503-8062-1/21/03.

https://doi.org/10.1145/3408877.3432448
ACM Reference Format:

Brett A. Becker, Amber Settle, Andrew Luxton-Reilly, Briana B. Morrison, and Cary Laxer. 2021. Expanding Opportunities: Assessing and Addressing Geographic Diversity at the SIGCSE Technical Symposium. In Proceedings of the 52nd ACM Technical Symposium on Computer Science Education (SIGCSE '21), March 13-20, 2021, Virtual Event, USA. ACM, New York, NY, USA, 7 pages. https://doi.org/10.1145/3408877.3432448

\section{INTRODUCTION}

For 51 years the SIGCSE Technical Symposium (referred to as the "Symposium" or "TS" in this paper) has been held in the continental United States. 2021 is the first time that the TS had been scheduled to be held outside the U.S. Ultimately the COVID-19 pandemic caused Toronto to be a virtual event. These facts combined with the 2021 theme of "Expanding Opportunities" provide a very appropriate reason to celebrate the fact that representative geographic participation in all SIGCSE conferences is crucial and the contributions of all can help SIGCSE move forward into uncharted waters. In addition to cultural richness and depth, wide geographic participation brings valuable perspectives on all areas of Computing Education. Wider geographic diversity is also almost guaranteed to improve all other types of diversity. Furthermore, other communities are recognizing that internationalization is part of inclusiveness [1]. As educators we expend significant effort internationalizing curricula and other aspects of our work [4, 9], and our research and practice communities should be equally globally-focused. We place importance on the sense of belonging of our students [18, 20], but possibly not as much on ourselves and each other. Finally, teaching computing in developing countries is fraught with challenges and biases not often faced in the U.S. [4, 7, 21]. Educators and students from all countries stand to benefit from participation at the TS.

SIGCSE, the Special Interest Group for Computer Science Education, is one of the oldest and largest SIGs of the Association for Computing Machinery (ACM), having celebrated its $50^{\text {th }}$ anniversary in 2018 [5]. SIGCSE is a global organization with members in well over 100 countries. SIGCSE currently has local chapters outside the U.S. in: Australasia, China, India, Ireland, Jataí (Brazil) and the United Kingdom. However, attendance at SIGCSE conferences is not always reflective of membership as a whole [22,30].

The TS is the oldest of the SIGCSE conferences, having celebrated its $50^{\text {th }}$ anniversary in 2019. U.S. attendance at the TS is typically more than $92 \%$ [30]. The second-oldest SIGCSE conference is the 
Annual Conference on Innovation and Technology in Computer Science Education (ITiCSE), which celebrated its $25^{\text {th }}$ anniversary in 2020. ITiCSE is typically held in or around Europe, and attracts a more geographically diverse group of attendees with between 30 and $46 \%$ U.S. attendees [30]. The third-oldest is the Annual ACM International Computing Education Research (ICER) conference which rotates every four years from North America to Europe to North America again on the way to Australasia. The newest SIGCSE conference, the ACM Global Computing Education Conference (CompEd), was created to serve locations without a regular SIGCSE conference. Held every other year, the first (2019) was in China and 2021 was scheduled to be hosted in India but has been postponed until at least 2022 due to the pandemic. CompEd 2019 attracted attendees from across the globe with no single country dominating apart from the host country which made up approximately $1 / 3$ of attendees. The 2019 attendances of these conferences were: SIGCSE: 1809; ITiCSE: 274; ICER: 152 ; and CompEd: $154{ }^{1}$

While all four SIGCSE conferences are successful, with record attendances in recent years, there is reason to be concerned about geographic representation. First, these conferences are the most common outlet for research in the community, and if participation in those conferences is geographically limited the research may not include or reach everyone it should. Furthermore, one of the benefits of conference attendance is networking, and if SIGCSE members from certain countries are not present it may stifle innovation for the community as a whole, particularly at a time when computing is increasingly seen as operating in a global context [11]. SIGCSE conferences also help drive membership, which is crucial for the health and future of the organization.

\section{RELATED WORK}

This paper continues a tradition of Computing Education papers that reflect on the nature of our community - either focusing on the composition of people in the community, or on the artifacts created by the community. Several previous papers have attempted to understand the Computing Education community by analyzing conference proceedings to determine topics $[23,24,27,28]$ or research methods $[3,14]$ of interest to the community. Others survey the community to identify interests [10], attitudes towards research [2], or to identify trends such as making learning more appropriate from gender, diversity, accessibility and inclusion standpoints $[8,13,19]$.

Of direct relevance to this work is literature that focuses on the members of the community themselves, and how they contribute to our conferences. An analysis of the collaboration networks within six Computing Education conferences (ACE, FIE, ITiCSE, Jenui, SEE and the Symposium) revealed that authors tend to write papers with fewer co-authors than is typical in other computing disciplines. Those authors are more often existing members of the community compared with other computing disciplines. Although the Computing Education community has a reputation for being welcoming, the on-boarding of newcomers into our community does not tend to occur through collaborative co-authoring of papers. The authors conclude that our community tends to be "introverted" and lacks the global outlook that is needed to make progress [17].

\footnotetext{
${ }^{1}$ Susan Rodger maintains a history of SIGCSE conferences originally started by Henry Walker at https://users.cs.duke.edu/ rodger/sigcseconferences.html.
}

Interestingly, a detailed analysis of the ICER conference indicates that it is atypical of other Computing Education conferences such as the TS. ICER has relatively high rates of collaboration among authors, including collaborations between authors from different institutions and different countries, and a steady influx of new authors, many of whom are co-authoring papers with established members of the community [26]. Although the majority of authors are from the U.S., almost half of the authors are from outside of the U.S. An analysis of Koli Calling (Koli) also found significant evidence of collaboration between authors. Although the majority of authors publishing at Koli are from Finland, close to half of the authors are from other countries [25]. Nonetheless, an ICER 2020 paper showed that the vast majority of K-12 research occurred in, and with study participants from, the highest-income countries [4].

ITiCSE Working Group reports are (unsurprisingly due to their size alone) much more collaborative than typical Computing Education conference publications. This collaboration is welcoming to newcomers, with approximately $94 \%$ of reports including both newcomers and 'old-timers' who have established networks within the community. Approximately half of working group authors are newcomers, and slightly more than half of working groups contain a least four 'old-timers', ensuring that large numbers of newcomers can rapidly build multiple connections with the community [16].

Although prior work has investigated the nature of publications at the TS, to our knowledge there is no previous work that analyzes the global nature of the community and the TS.

\section{METHODOLOGY}

We collected data from multiple sources on ACM membership, SIGCSE membership, TS registrations, and the TS proceedings. ${ }^{2}$ Membership information for ACM and SIGCSE were obtained via email from the SIGCSE representative at ACM. The data was provided in a spreadsheet listing membership numbers for each country in each year between 2002 and 2019. To match the available data from the TS, only the data from 2010 to 2019 was considered. In order to use the data, we agreed to not include information about countries with very few members for purposes of maintaining anonymity. Information about the continents for each country was not provided by ACM and was produced by the authors.

Data for TS registrations were obtained from the registration team for the years 2010-2019. We did not include 2020 data because the Symposium was canceled due to the COVID-19 pandemic and numbers were changing rapidly up until that moment. The registration team provided the authors with a spreadsheet containing the number of registered attendees per country.

The metadata for the TS proceedings 2010-2019 was obtained from the ACM Digital Library for analysis. A script was used to categorize the country of affiliation for each author of each publication. The script was manually checked against a sample of papers to ensure the total paper count and author affiliation was being correctly tabulated. Several publications have affiliations that do not explicitly list a country, but instead report only a region (e.g., state or province) or an institution. In such cases, the location of

${ }^{2}$ Other than for historical comparisons, all data is 2010-2019 inclusive as attendance data is not available prior to 2010 . 
the region or institution was identified manually and tabulated as belonging to the corresponding country.

For each publication, the country was counted once for each time it appeared in an author affiliation. For example, if an article had five authors then it would be counted as having five participating authors and the country of each author affiliation would be tabulated. If the same people appeared as authors in other publications, then they would be counted again. In other words, the analysis of publication data does not focus on unique authors, but rather it represents the relative involvement of those authors. This is consistent with what Simon calls complete counting [26], which he suggests might be more indicative of engagement with the community than other ways to calculate authorship contributions.

\section{DATA ANALYSIS AND RESULTS}

\subsection{ACM Membership}

Since SIGCSE is associated with ACM, it is useful for context to consider the geographic distribution of members in ACM. As of July 2020 ACM had 74,442 professional members. Although ACM is a global organization, a near majority of its members (49\%) are from the U.S. $54 \%$ of members are from North America, with $24 \%$ from Asia, $17 \%$ from Europe, $2 \%$ from South America, $2 \%$ from Oceania and $1 \%$ from Africa.

\subsection{SIGCSE Membership}

In 1968 a group of computing educators met at the Fall Joint Computer Conference in Las Vegas to write and sign a petition that led to the creation of SIGCSE. By 1970, the year of the first Symposium, SIGCSE membership had grown to over 600 members, all of whom were listed in the December 1970 issue of the SIGCSE Bulletin [15]. After removing 29 institutional memberships (all in the U.S.) and a duplicate, there were 603 members from 29 countries as shown in Table 1. In total there were 54 members from outside the U.S. and Canada, representing $9 \%$ of the membership base.

Table 1: Countries with SIGCSE member counts (\#) and percentages in December 1970 [15]

\begin{tabular}{lrr}
\hline Country & $\#$ & $\%$ \\
\hline U.S. & 521 & 86 \\
Canada & 28 & 5 \\
Australia & 7 & 1 \\
Netherlands & 5 & $<1$ \\
Austria, England, Finland, Japan & 3 ea. & $<1$ ea. \\
Argentina, Belgium, Brazil, Denmark, Germany, Italy, & 2 ea. & $<1$ ea. \\
Mexico, South Africa, Switzerland & & \\
Czechoslovakia, France, Israel, New Zealand, & 1 ea. & $<1$ ea. \\
Norway, Portugal, Scotland, Spain, Sweden, Uganda, & & \\
Wales, Zambia & & \\
\hline
\end{tabular}

SIGCSE membership grew significantly after its establishment in the late 1960s. SIGCSE is currently the third largest ACM SIG with 2398 members as of December 2019. Table 2 shows average SIGCSE membership by country between 2010 and 2019. The vast majority $(82.1 \%)$ of SIGCSE members reside in the U.S. and Canada,
Table 2: Average SIGCSE membership 2010-19

\begin{tabular}{lll|lll}
\hline Country & $\#$ & $\%$ & Country & $\#$ & $\%$ \\
\hline U.S. & 2110.7 & 81.53 & Finland & 10.2 & 0.39 \\
Canada & 73.3 & 2.83 & China & 9.3 & 0.36 \\
United Kingdom & 53.1 & 2.05 & Italy & 9.1 & 0.35 \\
Australia & 41.4 & 1.60 & Switzerland & 9.0 & 0.34 \\
Germany & 28.6 & 1.10 & Mexico & 8.3 & 0.32 \\
Japan & 21.6 & 0.83 & Ireland & 7.6 & 0.29 \\
Spain & 17.4 & 0.67 & Norway & 7.0 & 0.27 \\
Sweden & 17.4 & 0.67 & South Africa & 7.0 & 0.27 \\
Brazil & 14.3 & 0.55 & Portugal & 6.8 & 0.26 \\
New Zealand & 12.8 & 0.49 & Austria & 6.2 & 0.24 \\
Israel & 12.2 & 0.47 & Republic of Korea & 5.4 & 0.21 \\
India & 11.7 & 0.45 & Denmark & 5.2 & 0.20 \\
Netherlands & 10.3 & 0.40 & Turkey & 5.1 & 0.20
\end{tabular}

There are 70 countries with SIGCSE membership averaging $>0$ and $<=5$ between 2010 and 2019 .

as shown in Figure 1. SIGCSE is skewed toward U.S. membership even more than ACM as a whole, which is currently $50.6 \%$ non-U.S.

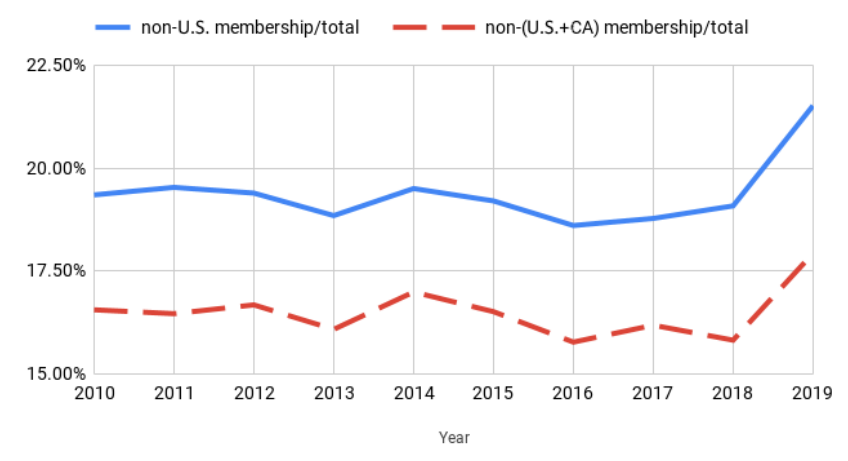

Figure 1: SIGCSE membership excluding the U.S. 2010-19

\subsection{Technical Symposium Attendance}

The TS was the first conference organized by SIGCSE. The first TS was held on the 16th of November, 1970 in Houston, Texas, U.S. and had 143 attendees. "Over 40" papers were submitted with 18 accepted [12]. In 2019 the $50^{\text {th }}$ TS was held with 1809 attendees and 994 submissions from over 50 countries, with a total of 2668 unique authors representing over 800 institutions. There were 526 paper submissions, with 169 accepted.

The TS is the flagship event of the SIGCSE calendar, and TS attendance has grown much faster than membership. In 2010 TS attendance / SIGCSE membership was $44 \%$ and by 2019 it was at $75 \%$. In addition to presentations, the TS incorporates several activities important to the SIG such as one of the two in-person executive board meetings of the year, presentation of some SIGCSE awards, and the annual SIGCSE business meeting.

Attendance at the TS is even more skewed toward U.S. attendees than overall SIGCSE membership. For the last decade (2010-19) the average U.S. attendance at the TS is $93 \%$. Canada represents an average of $2 \%$. All other countries (a total of 65 in number) 
account for only $4 \%$ of attendees. Figure 2 shows the attendance at the TS between 2010 and 2019 excluding members from the U.S. This demonstrates that the TS does not have geographically diverse attendance. For comparison, $\mathrm{CHI}$, the flagship conference of SIGCHI (the second largest ACM SIG) had an average non-U.S. attendance of $57 \%$ from 2008-2015 inclusive (2015 is last date data was found) [29]. Although CHI is often held outside the U.S., even when it is held in the U.S. the non-U.S. attendance averages $44 \%$. However, comparing these conferences is difficult, since $\mathrm{CHI}$ is often held outside North America and is more research-focused than the TS. It may be that CHI compares more readily to ICER which is more geographically diverse than the TS.

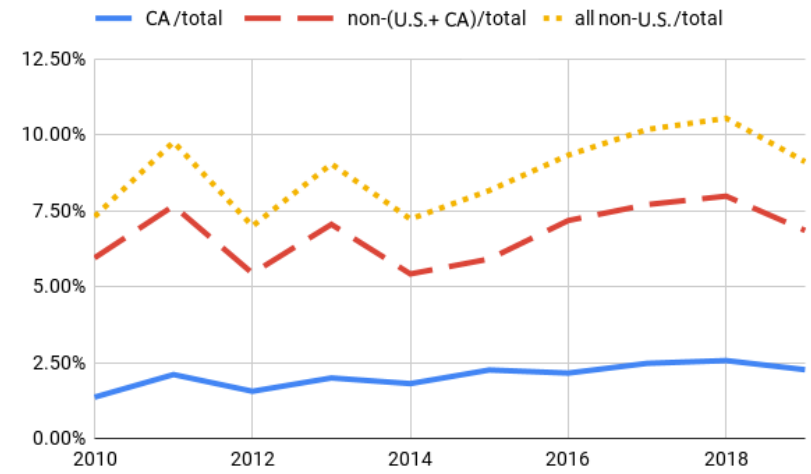

Figure 2: Symposium attendance 2010-19 excluding the U.S.

North American dominance at the TS is particularly obvious when attendance is aggregated by continent as shown in Figure 3, which represents 13,580 TS attendees from 2010-2019.

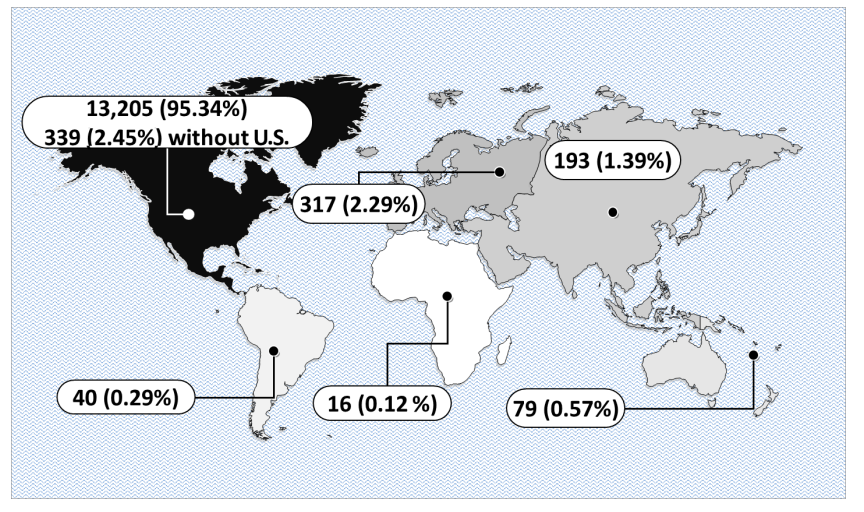

Figure 3: Symposium attendance by continent, 2010-19

To understand the proportion of SIGCSE members from various geographical areas attending the TS, it makes sense to consider the average TS attendance divided by the average SIGCSE membership for that area. In Figure 4, the average attendance at the TS from 2010 and 2019 is divided by the average number of members in that area in the same time period.

As is seen in Figure 4, a higher proportion of Americans attend the TS than all SIGCSE members combined. The next closest group

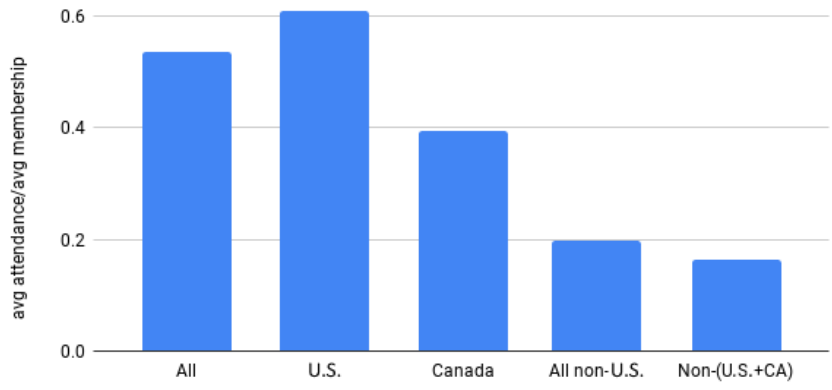

Figure 4: Average Symposium attendance divided by average SIGCSE membership 2010-19

of attendees are Canadians, and attendees from all other countries lag well behind. Thus, even when TS attendance is considered relative to membership, U.S. participation remains high.

\subsection{Symposium Publications and Authorship}

Just as Americans dominate TS attendance, the majority of publications at the TS are authored by Americans. Table 3 shows the percentage of all contributions (e.g., all authors of all publications in the TS proceedings), the percentage of full papers, and the percentage of non-paper contributions) by country from 2010-2019. Only countries contributing more than $1 \%$ of papers are shown individually. Note that non-papers include keynotes, panels, posters, birds of a feather, workshops, student research competitions demonstrations, special sessions, etc. Obviously, authorship at the Symposium is not geographically diverse.

Table 3: All Symposium Papers 2010-19

\begin{tabular}{lrrr}
\hline & \multicolumn{3}{c}{ \% contributions } \\
Country & all & papers & non-papers \\
\hline U.S. & 86.9 & 78.9 & 93.2 \\
Canada & 3.1 & 4.7 & 1.9 \\
United Kingdom & 1.4 & 2.2 & 0.7 \\
Finland & 0.8 & 1.7 & 0.0 \\
Australia & 1.0 & 1.6 & 0.6 \\
Brazil & 0.6 & 1.3 & 0.1 \\
New Zealand & 0.7 & 1.2 & 0.3 \\
Germany & 0.7 & 1.0 & 0.5 \\
All other countries & 4.8 & 7.4 & 2.8 \\
\hline
\end{tabular}

Looking deeper at submission type, it emerges that non-U.S. authors are often more focused on full papers compared to other submission types. Put the other way, U.S. authors are particularly dominant in non-paper contributions. Authors from a significant number of countries focus solely on paper publications. This is problematic for participation as the paper tracks often have the lowest acceptance rates. It is likely that publishing anything but full papers does not warrant travel as the cost can't be justified for other contribution types. Table 4 shows countries ranked by the percentage of authors involved in TS publications that are full papers. For example, a country that has only had papers appear in the proceedings between 2010 and 2019 would have a 100\% paper 
Table 4: Countries grouped by \% full paper contribution, calculated as: number of full papers / total number of contributions at the TS 2010-19 (left column). For example a country with 10 author contributions to papers and 0 author contributions to other publication types has a $\mathbf{1 0 0 \%}$ paper contribution. Countries with $\leq 10$ contributions are not named.

\begin{tabular}{|c|c|c|c|c|}
\hline $\begin{array}{l}\% \text { full paper } \\
\text { contrib. }\end{array}$ & country (\# total contrib.) & $\begin{array}{r}\text { \# countries with } \\
\text { contrib. } \leq 10\end{array}$ & $\begin{array}{r}\text { \# countries } \\
\text { sum }\end{array}$ & $\begin{array}{r}\text { contrib. } \\
\text { sum }\end{array}$ \\
\hline $66.6 \leq \% \leq 100$ & $\begin{array}{l}\text { Australia (87); Brazil (54); Chile (19), Finland (66); Ireland (24); Israel (40); Netherlands (32); } \\
\text { New Zealand (61); Norway (12); Spain (17); Sweden (21); Switzerland (16); U.K. (118) }\end{array}$ & 21 & 34 & 623 \\
\hline $33.3 \leq \% \leq 66.6$ & $\begin{array}{l}\text { Canada (268); Czech Republic (15); France (15); Germany (62); India (17); Italy (14); Japan (28); } \\
\text { U.S. (7495) }\end{array}$ & 3 & 11 & 7936 \\
\hline $0 \leq \% \leq 33.3$ & China (28); Mexico (13) & 7 & 9 & 65 \\
\hline
\end{tabular}

contribution. Countries with authors that tend to contribute more overall (e.g., countries with author contributions $>50$ ) also tend to publish items that are not full papers, with Australia, Finland, New Zealand, and the U.K. being notable exceptions. Thirty-four countries $(63 \%)$ represent the top third of full paper contributions (based on percentage). However, these 34 countries are only responsible for only $7 \%$ (623) of the total TS contributions. This group also has the most countries (21, or $68 \%$ ) that have published 10 or fewer contributions. The U.S., with $87 \%$ of total TS contributions, has only $40 \%$ full paper contribution.

Although the percentage of U.S. authors publishing papers is approximately the same as the percentage of U.S. members, the authors are more highly represented in other types of contributions. Several other countries, such as Brazil, Canada, Finland, and New Zealand appear to be contributing well above the amount expected based on their proportion of members, while many other countries with members belonging to SIGCSE publish infrequently. This provides evidence that TS authorship is also not diverse, but also less uniformly distributed compared to SIGCSE and ACM membership.

\section{SYMPOSIUM ENGAGEMENT INITIATIVES}

The SIGCSE Board and TS organizers have long recognized both the importance of global participation in the conference and the dominance of U.S. attendees and authors. In this section we only discuss initiatives specific to the TS, not SIGCSE in general.

\subsection{Global Committee}

In 1996 the TS organizers established an International Liaison role on the conference committee, a role that has been consistently filled since 2000 . Recognizing that broader impact could be achieved by a larger group, the TS International Committee was established in 2014. The committee is tasked with spreading word about the TS among computing educators around the globe and encouraging people from their regions to attend. Members of the committee are not offered compensation, but are listed on the conference website as part of the conference committee. The committee is slowly rotated by incoming Liaisons.

One of the main events organized by the Liaison is a lunch for "international" participants at the TS, typically held off-site. In the first year there were 13 attendees. After 2014, at the request of the committee, the lunch was added to the program, and in the intervening years attendance has grown considerably. In 2019 the lunch had 64 attendees. Notably that was the first year that conference registrants could sign up for the lunch when registering online, and due to its size the lunch was held on site at the conference center.

In 2020, the term "International" was abandoned for the term "Global" to better capture the notion of SIGCSE being an organization with members from across the world. Thus the terminology is now Global Liaison, Global Committee, and Global Lunch.

\subsection{Funding}

Obtaining funding for conferences is a challenge for many SIGCSE members. In an effort to attract new attendees the SIGCSE Board established a Travel Grant program in 2014. The program was the brainchild of Henry Walker and was funded for several years by his donations. Faculty and teachers who have never attended the TS are eligible to apply for up to $\$ 500$ of funding and free registration to the conference. In all but the first year of the Travel Grant's offering, at least one person from outside the U.S. has received an award, although most of the awards have gone to Americans. In late 2019, the Travel Grant committee changed the rubric used for evaluating applicants, prioritizing those from low-resource institutions and those from groups not broadly represented at the TS, including applicants from outside the U.S. Among the 20 awards given in 2020 , seven recipients were located outside the U.S.

\section{IMPROVING SYMPOSIUM ENGAGEMENT}

In this section we discuss possible solutions to help improve geographic diversity at the SIGCSE Technical Symposium.

\subsection{Organization / Administrative}

Given that almost all academics are involved in teaching, SIGCSE could arguably have the largest potential audience of any SIG. It is telling that the percentage of non-U.S. membership in SIGCSE is much lower than in ACM overall, despite the relatively low costs of joining SIGCSE. This suggests that non-U.S. academics may value SIGCSE less than other more technical disciplinary areas. We speculate that teaching is highly contextualized, and a SIG focused on issues that are primarily of interest to a limited geographic region may be perceived as being of lower value to a global audience. Additionally, because so few computing faculty members receive their advanced degrees in Computing Education or are trained in 
Computing Education research, it may have less value. We suggest exploring the following:

- Collect and report more data on participation at all levels of SIGCSE, including the TS - this may include a dedicated role.

- Re-examine the role of the TS Global Committee and investigate if more financial or other support is required to promote greater engagement with the global community.

- Actively encourage more non-U.S. membership in SIGCSE, perhaps with a stronger emphasis on creating local chapters that can act as catalysts for greater interest. Encourage non-U.S. members who attend the TS to share with local chapter members their experiences that can be adapted or implemented, such as the next "big ideas" in Computing Education.

- Increase initiatives to recruit non-U.S. PhD students as SIGCSE members. These students are likely future academics, so investing in a positive relationship between the students and the organization may be an effective method of growing non-U.S membership rates over time. Offering reduced TS registration the year after participating in a doctoral consortium might encourage more Computing Education $\mathrm{PhD}$ students to attend.

\subsection{Authorship}

Despite the overall contribution of non-U.S. authors being quite low, the international community makes a greater contribution to full papers than to contributions archived in the proceedings. To increase non-U.S. contributions, we need to encourage non-U.S. authors to see the value in contributing non-paper forms of dissemination to the TS, and to encourage TS participants to appreciate non-U.S. contributions. If there is a clear demand for more international perspectives, it seems likely that non-U.S. members of the community will respond. Some possible avenues to pursue are:

- Members of the community could actively seek collaborators from other countries and invite them to participate in nonpaper contributions, which can have lower barriers to entry. For example, all panels and special sessions might seek to include at least one non-U.S. participant. This could improve the quality of work by increasing the diversity of perspectives and offer advantageous international collaborations.

- The call for participation for the TS could be adapted to include a greater emphasis on global perspectives, international participation, and multi-national collaborations.

\subsection{Reviewing}

Many aspects of the review process rely on subjective judgment and are prone to intrinsic bias. TS papers dealing with issues related specifically to U.S. culture or administrative structures (e.g., AP exams) are common, and papers that focus on issues specific to other countries (e.g., national exams in countries not typically represented at the TS) can possibly be seen as being less 'relevant'. We suggest the recruitment of sufficient reviewers from outside the U.S., and developing resources that provide explicit training for reviewers with guidelines about global perspectives.

\subsection{Funding / Attendance / Experiences}

For U.S. attendees, registration and accommodation are typically the largest costs involved in attending the TS. For non-U.S. attendees, transportation costs can exceed all other costs combined. However, this alone does not explain low non-U.S. participation in the TS. For example, Australasians make a proportionally larger contribution to Koli (24.7 weighted contribution to papers, or approximately $7 \%$ of the conference) [25] despite the cost of travel to Koli being typically higher than to the TS. We suggest:

- Modify the Travel Grant program to allow those from outside the U.S. to receive more than $\$ 500$ in travel support. This may help to increase the pipeline of first-time non-U.S. participants.

- Create a new travel fund to support attendees, possibly including repeat-attendees, from countries outside of North America. Funds could be created by the SIGCSE Board, local chapters, and sponsoring organizations.

- Advertise travel grants more widely, including through local chapters and other channels.

- Investigate alternative means of "attending" the TS, perhaps virtually, to reduce costs. While virtual attendance will never be comparable to physical, conferences held virtually due to COVID-19 have seen increased registration rates, likely due to lower cost and no travel requirements. Engagement however, needs to justify the financial and time commitments.

Improving the experience of non-U.S. attendees may gradually increase participation rates. In 2020, a buddy system was piloted to allow non-U.S. registrants to be paired up with more experienced attendees who volunteered to act as 'buddies'. The pilot was a success, with $41 \%$ of non-U.S. registrants being paired-up, either as a non-U.S.-based attendee looking to be paired with a more experienced attendee, or vice-versa, with a total of 119 people in 59 pairs from 16 countries [6]. Unfortunately due to the cancellation of the 2020 TS most pairs never physically met up, but the pilot was a promising start. The program is running again for 2021 with some modifications, as the 2021 TS is being held virtually.

\subsection{Recognition / Awards}

Awards and other forms of recognition are valuable academic currency. We suggest that the community consider endorsing awards that encourage non-U.S. participation. An award for "best multinational paper" or "best global perspective" may encourage collaboration between authors from different countries and broaden the level of non-U.S. participation.

\section{CONCLUSIONS}

We conclude with what was already known - the SIGCSE Symposium is not geographically diverse as it should, and arguably needs, to be. However, using attendee registration, authorship, and membership data we support this conclusion with data, and offer suggestions to improve the situation. We found that non-U.S. membership in SIGCSE is lower than that of the ACM; the proportion of non-U.S. attendees at the Symposium is extremely low; and that U.S. and non-U.S. attendees engage in authorship differently, particularly in percentages of full paper and non-paper contributions. If SIGCSE and the Symposium aim to be internationally relevant and representative, we need to be working much harder to bring members from all corners of the globe into our community and to ensure greater inclusivity of international perspectives at the flagship SIGCSE conference. 


\section{REFERENCES}

[1] 2017. SIGCHI-EC Meeting Minutes Edinbourgh. https://sigchi.org/wp-content/ uploads/2017/03/SIGCHI-EC-meeting-notes-201608.pdf

[2] Alireza Ahadi, Arto Hellas, Petri Ihantola, Ari Korhonen, and Andrew Petersen 2016. Replication in Computing Education Research: Researcher Attitudes and Experiences. In Proceedings of the 16th Koli Calling International Conference on Computing Education Research (Koli Calling '16). ACM, New York, NY, USA, 2-11. https://doi.org/10.1145/2999541.2999554

[3] Ahmed Al-Zubidy, Jeffrey C. Carver, Sarah Heckman, and Mark Sherriff. 2016 A (Updated) Review of Empiricism at the SIGCSE Technical Symposium. In Proceedings of the 47th ACM Technical Symposium on Computing Science Education (SIGCSE '16). ACM, New York, NY, USA, 120-125. https://doi.org/10.1145/ 2839509.2844601

[4] Tehreem Anwar, Arturo Jimenez, Arsalan Bin Najeeb, Bishakha Upadhyaya, and Monica M. McGill. 2020. Exploring the Enacted Computing Curriculum in K-12 Schools in South Asia: Bangladesh, Nepal, Pakistan, and Sri Lanka. In Proceedings of the 2020 ACM Conference on International Computing Education Research (ICER '20). Association for Computing Machinery, New York, NY, USA, 79-90. https://doi.org/10.1145/3372782.3406251

[5] Mark Bailey and Laurie Smith King (Eds.). 2018. ACM Inroads 9, 4 (2018). https: //doi.org/10.1145/3290216

[6] Brett A. Becker. 2020. SIGCSE 2020 International Buddy Program - Final (Record) Numbers. https://cszero.wordpress.com/2020/04/04/sigcse-2020-internationalbuddy-program-final-record-numbers/

[7] Brett A. Becker and Thomas Fitzpatrick. 2019. What Do CS1 Syllabi Reveal About Our Expectations of Introductory Programming Students? In Proceedings of the 50th ACM Technical Symposium on Computer Science Education (SIGCSE '19). Association for Computing Machinery, New York, NY, USA, 1011-1017. https://doi.org/10.1145/3287324.3287485

[8] Brett A. Becker and Keith Quille. 2019. 50 Years of CS1 at SIGCSE: A Review of the Evolution of Introductory Programming Education Research. In Proceedings of the 50th ACM Technical Symposium on Computer Science Education (SIGCSE '19). Association for Computing Machinery, New York, NY, USA, 338-344. https: //doi.org/10.1145/3287324.3287432

[9] Hans de Wit and Elspeth Jones. 2018. Inclusive Internationalization: Improving Access and Equity. International Higher Education 94 (2018), 16-18.

[10] Paul Denny, Brett A. Becker, Michelle Craig, Greg Wilson, and Piotr Banaszkiewicz. 2019. Research This! Questions That Computing Educators Most Want Computing Education Researchers to Answer. In Proceedings of the 2019 ACM Conference on International Computing Education Research (ICER '19). ACM, New York, NY, USA, 259-267. https://doi.org/10.1145/3291279.3339402

[11] Sarah Douglas, Art Farley, Ginnie Lo, Andrzej Proskurowski, and Michal Young. 2010. Internationalization of Computer Science Education. In Proceedings of the 41st ACM Technical Symposium on Computer Science Education (SIGCSE '10). ACM, New York, NY, USA, 411-415. https://doi.org/10.1145/1734263.1734404

[12] Maureen Doyle. 2015. SIGCSE Symposium History. SIGCSE Bull. 47, 4 (Dec. 2015), 7-8. https://doi.org/10.1145/2856332.2856338

[13] Andrew Luxton-Reilly, Simon, Ibrahim Albluwi, Brett A. Becker, Michail Giannakos, Amruth N. Kumar, Linda Ott, James Paterson, Michael James Scott, Judy Sheard, and Claudia Szabo. 2018. Introductory Programming: A Systematic Literature Review. In Proceedings Companion of the 23rd Annual ACM Conference on Innovation and Technology in Computer Science Education (ITiCSE 2018 Companion). Association for Computing Machinery, New York, NY, USA, 55-106. https://doi.org/10.1145/3293881.3295779

[14] Lauri Malmi, Judy Sheard, Simon, Roman Bednarik, Juha Helminen, Ari Korhonen, Niko Myller, Juha Sorva, and Ahmad Taherkhani. 2010. Characterizing Research in Computing Education: A Preliminary Analysis of the Literature. In Proceedings of the Sixth International Workshop on Computing Education Research (ICER '10). ACM, New York, NY, USA, 3-12. https://doi.org/10.1145/1839594.1839597
[15] David Matula. 1970. Who's in SIGCSE. SIGCSE Bull. 2, 5 (1970).

[16] Robert McCartney and Kate Sanders. 2018. ITiCSE Working Groups and Collaboration in the Computing Education Community. In Proceedings of the 23rd Annual ACM Conference on Innovation and Technology in Computer Science Education (ITiCSE 2018). ACM, New York, NY, USA, 332-337. https: //doi.org/10.1145/3197091.3197143

[17] Joe Miró Julià, David López, and Ricardo Alberich. 2012. Education and Research: Evidence of a Dual Life. In Proceedings of the Ninth Annual International Conference on International Computing Education Research (ICER '12). ACM, New York, NY, USA, 17-22. https://doi.org/10.1145/2361276.2361281

[18] Catherine Mooney, Anna Antoniadi, Ioannis Karvelas, Lána Salmon, and Brett A. Becker. 2020. Exploring Sense of Belonging in Computer Science Students. In Proceedings of the 2020 ACM Conference on Innovation and Technology in Computer Science Education (ITiCSE '20). Association for Computing Machinery, New York, NY, USA, 563. https://doi.org/10.1145/3341525.3393974

[19] Catherine Mooney and Brett A. Becker. 2020. Sense of Belonging: The Intersectionality of Self-Identified Minority Status and Gender in Undergraduate Computer Science Students. In United Kingdom \& Ireland Computing Education Research Conference. (UKICER '20). Association for Computing Machinery, New York, NY, USA, 24-30. https://doi.org/10.1145/3416465.3416476

[20] An Nguyen and Colleen M Lewis. 2020. Competitive Enrollment Policies in Computing Departments Negatively Predict First-Year Students' Sense of Belonging, Self-Efficacy, and Perception of Department. In Proceedings of the 51st ACM Technical Symposium on Computer Science Education. 685-691.

[21] Josephat O Oroma, Herbert Wanga, and Fredrick Ngumbuke. 2012. Challenges of Teaching and Learning Computer Programming in Developing Countries: Lessons from Tumaini University. In Proceedings of INTED2012 conference. 5th7th march 2012, Valencia, Spain.

[22] Amber Settle, Brett A. Becker, Rodrigo Duran, Viraj Kumar, and Andrew LuxtonReilly. 2020. Improving Global Participation in the SIGCSE Technical Symposium: Panel. In Proceedings of the 51st ACM Technical Symposium on Computer Science Education (SIGCSE '20). Association for Computing Machinery, New York, NY, USA, 483-484. https://doi.org/10.1145/3328778.3366979

[23] Simon. 2007. A Classification of Recent Australasian Computing Education Publications. Computer Science Education 17, 3 (2007), 155-169. https://doi.org/ 10.1080/08993400701538021 arXiv:https://doi.org/10.1080/08993400701538021

[24] Simon. 2009. Ten Years of the Australasian Computing Education Conference. In Proceedings of the Eleventh Australasian Conference on Computing Education Volume 95 (ACE '09). Australian Computer Society, Inc., Darlinghurst, Australia, Australia, 157-164. http://dl.acm.org.ezproxy.auckland.ac.nz/citation.cfm?id= 1862712.1862735

[25] Simon. 2016. The Koli Calling Community. In Proceedings of the 16th Koli Calling International Conference on Computing Education Research (Koli Calling '16). ACM, New York, NY, USA, 101-109. https://doi.org/10.1145/2999541.2999562

[26] Simon. 2016. A Picture of the Growing ICER Community. In Proceedings of the 2016 ACM Conference on International Computing Education Research (ICER '16). ACM, New York, NY, USA, 153-159. https://doi.org/10.1145/2960310.2960323

[27] Simon, Angela Carbone, Michael de Raadt, Raymond Lister, Margaret Hamilton, and Judy Sheard. 2008. Classifying Computing Education Papers: Process and Results. In Proceedings of the Fourth International Workshop on Computing Education Research (ICER '08). ACM, New York, NY, USA, 161-172. https://doi.org/10.1145/1404520.1404536

[28] David W. Valentine. 2004. CS Educational Research: A Meta-analysis of SIGCSE Technical Symposium Proceedings. In Proceedings of the 35th SIGCSE Technical Symposium on Computer Science Education (SIGCSE '04). ACM, New York, NY, USA, 255-259. https://doi.org/10.1145/971300.971391

[29] SIGCHI Conferences VP. 2019. SIGCHI Conference History. https://sigchi.org/ conferences/conference-history/

[30] Ellen Walker, Amber Settle, and Steve Zilora. 2017. News from the SIGs. ACM Inroads 8, 2 (May 2017), 6-8. https://doi.org/10.1145/3080623 